Article

\title{
Alcohol Exposure Alters Mouse Lung Inflammation in Response to Inhaled Dust
}

\author{
Michael L. McCaskill ${ }^{1}$, Debra J. Romberger ${ }^{1,2,3}$, Jane DeVasure ${ }^{3}$, Jessica Boten ${ }^{3}$, \\ Joseph H. Sisson ${ }^{3}$, Kristina L. Bailey ${ }^{3}$, Jill A. Poole ${ }^{3}$ and Todd A. Wyatt ${ }^{1,2,3, *}$
}

1 Department of Environmental, Agricultural, and Occupational Health, College of Public Health, University of Nebraska Medical Center, Omaha, NE 68198, USA;

E-Mails: mmccaskill@unmc.edu (M.L.M.); dromberg@unmc.edu (D.J.R.)

2 VA Nebraska-Western Iowa Health Care System Research Service, Department of Veterans Affairs Medical Center, 4101 Woolworth Avenue, Omaha, NE 68105, USA

3 Pulmonary, Critical Care, Sleep \& Allergy Division, Department of Internal Medicine, 985300

Nebraska Medical Center, Omaha, NE 68198, USA; E-Mails: jdevasure@unmc.edu (J.D.); Jessica.boten@unmc.edu (J.B.); jsisson@unmc.edu (J.H.S.); kbailey@unmc.edu (K.L.B.); japoole@unmc.edu (J.A.P.)

* Author to whom correspondence should be addressed; E-Mail: twyatt@unmc.edu; Tel.: +1-402-559-3817; Fax: +1-402-559-6584.

Received: 5 March 2012; in revised form: 21 June 2012 / Accepted: 26 June 2012 /

Published: 4 July 2012

Abstract: Alcohol exposure is associated with increased lung infections and decreased mucociliary clearance. Occupational workers exposed to dusts from concentrated animal feeding operations (CAFOs) are at risk for developing chronic inflammatory lung diseases. Agricultural worker co-exposure to alcohol and organic dust has been established, although little research has been conducted on the combination effects of alcohol and organic dusts on the lung. Previously, we have shown in a mouse model that exposure to hog dust extract (HDE) collected from a CAFO results in the activation of protein kinase $\mathrm{C}$ (PKC), elevated lavage fluid cytokines/chemokines including interleukin-6 (IL-6), and the development of significant lung pathology. Because alcohol blocks airway epithelial cell release of IL-6 in vitro, we hypothesized that alcohol exposure would alter mouse lung inflammatory responses to HDE. To test this hypothesis, C57BL/6 mice were fed $20 \%$ alcohol or water ad libitum for 6 weeks and treated with 12.5\% HDE by intranasal inhalation method daily during the final three weeks. Bronchoalveolar lavage fluid (BALF), tracheas and lungs were collected. HDE stimulated a 2-4 fold increase in lung and tracheal PKC $\varepsilon$ (epsilon) 
activity in mice, but no such increase in PKCe activity was observed in dust-exposed mice fed alcohol. Similarly, alcohol-fed mice demonstrated significantly less IL-6 in lung lavage in response to dust than that observed in control mice instilled with HDE. TNF $\alpha$ levels were also inhibited in the alcohol and HDE-exposed mouse lung tissue as compared to the HDE only exposed group. HDE-induced lung inflammatory aggregates clearly present in the tissue from HDE only exposed animals were not visually detectable in the HDE/alcohol co-exposure group. Statistically significant weight reductions and $20 \%$ mortality were also observed in the mice co-exposed to HDE and alcohol. These data suggest that alcohol exposure depresses the ability of the lung to activate PKCE-dependent inflammatory pathways to environmental dust exposure. These data also define alcohol as an important co-exposure agent to consider in the study of inhalation injury responses.

Keywords: alcohol; inflammation; mortality; organic dust

\section{Introduction}

The pulmonary system is exposed to inhaled toxins and pathogens as a result of respiration. In turn, the pulmonary system has developed innate inflammatory responses to defend against these foreign invaders. A few of these inflammatory responses, such as inflammatory cell recruitment, can be modulated by alcohol exposure [1-4]. While the liver metabolizes most consumed alcohol, a significant percentage is exhaled unchanged [5]. This pulmonary exposure to alcohol can damage the bronchial epithelial layer of the lung [6,7], while impairing the lung's ability to repair epithelial wounding via inhibition of the PKA pathway [8]. Additionally, alcohol inhibits the lipopolysaccharide (LPS)-induced inflammatory cytokine, interleukin-6 (IL-6), via the p38 ERK1/2 MAPK pathway [9]. It is also known that alcohol, at least in part, exerts its anti-inflammatory response via activation of the hypothalamic-pituitary-adrenal axis pathway resulting in increases of glucocorticoids [10]. Alcohol also interferes with proper inflammatory responses by disturbing the enzymatic processing of TNF $\alpha$ by TNF $\alpha$ Converting Enzyme (TACE) and abrogating TNFa/TACE function [11,12].

Animal husbandry is rife with occupational hazards. An emerging hazard is respiratory disease, including: occupation-related chronic bronchitis, chronic obstructive pulmonary disease (COPD), and exacerbation of asthma due to the inhalation of dust associated with swine husbandry [13]. This robust swine barn dust-induced inflammatory response is an essential component of the innate immune response. Historically, the trigger for the inflammatory response to swine dust exposure was attributed to endotoxins present in the dust [14]. However, recent publications describe an endotoxin-independent inflammatory effect in in vivo and in vitro swine barn dust exposures [15]. It is also well known that swine barn dust slows airway epithelial cell migration [16] and stimulates inflammatory cytokines IL-6 and IL-8 more potently than LPS [17-19].

Due to the changing socio-economic characteristics of American agricultural workers, old adages of the "healthy farmer" are dissipating. For instance, workers who are exposed to occupational organic dust also could be drinking significant volumes of alcohol. A Colorado State University farm-based occupational injury and alcohol consumption study [20] reports as high as $52 \%$ of the person days 
(8-h work day) surveyed involved two or more glasses of alcohol consumed. Another alcohol study conducted in rural Kentucky reports that $75 \%$ of those surveyed consumed alcohol to the point of intoxication at least three times a week for several years [21]. Midwestern states such as Nebraska and Iowa have some of the highest reported levels of rural alcohol usage (68\%) and binge drinking (45\%) for ages 18-25 in the United States [22].

Alcohol consumption leads to a muted pulmonary inflammatory response in alcohol-exposed rodents [23,24]. It is also known that hog confinement barn dust extract (HDE), when inhaled, leads to a severe pulmonary inflammatory response in C57BL/6 mice. We hypothesized that alcohol would depress the normative pro-inflammatory response observed in HDE-treated lungs. This study aims to evaluate in vivo effects on murine lung pathology and inflammatory cytokine response in alcohol-fed and HDE nasally instilled mice.

\section{Experimental Section}

\subsection{Mice}

Female C57BL/6 mice were purchased from the National Cancer Institute (Frederick, MD) at 7-8 weeks of age and under standard housing conditions. Mice were acclimated to the AAALAC-certified facility at the University of Nebraska Medical Center for 1 week before the start of exposure and received standard rodent chow ad libitum for the entire course of the study. Mice were monitored daily and weighed weekly. All experimental protocols were reviewed and approved by the Institutional Animal Care and Use Committee of the Omaha Veterans Affairs Medical Center. All protocols conformed to the Guide for the Care and Use of Laboratory Animals of the National Institutes of Health.

\subsection{Organic Dust Exposure}

Organic dust was collected from two different confinement swine barns containing at least 500 individual animals. The organic dust was then made into an extract (HDE) by methods previously described [25]. Mice received saline or HDE by an intranasal exposure method as previously established using 12.5\% $\mathrm{HDE}$ as an optimal concentration for eliciting lung inflammation [26]. Mice received daily nasal instillations of $12.5 \% \mathrm{HDE}$ for 3 weeks prior to sacrifice.

\subsection{Alcohol Feeding}

Mice receiving alcohol were given increasing concentrations of alcohol in water over a 2-week period until the target concentration of $20 \%$ was reached using the Meadows-Cook model [27,28]. Mice in the alcohol group were given $5 \%$ alcohol (wt/vol) to drink ad libitum and scaled up over two weeks to $20 \%$ alcohol (wt/vol) for 6 weeks [30]. Mice in the matched control group were given water from the same source without alcohol. The alcohol exposure model utilized is effective in achieving average blood alcohol concentration (BAC) levels of $149 \pm 47 \mathrm{mg} / \mathrm{dL}$ in the alcohol-fed mice [29]. 


\subsection{Bronchoalveolar Lavage (BAL)}

After the instillation period, mice were euthanized by intraperitoneal injection of $50 \mathrm{mg} / \mathrm{kg}$ body weight of pentobarbital Nembutol (Abbott Labs, Chicago, IL, USA). The trachea was exposed and a cannula inserted just below the larynx. The proximal end of the trachea was held around the cannula with forceps while $1.0 \mathrm{~mL}$ of sterile PBS (Gibco, Grand Island, NY, USA) was instilled into the lungs and recovered by aspiration. A total of $3.0 \mathrm{~mL}$ was introduced to the lungs. The BAL fluid was centrifuged at $250 \mathrm{~g}$ to collect cells. The supernatant from the first milliliter of BAL fluid recovered was frozen at $-80{ }^{\circ} \mathrm{C}$ to later test for cytokines. Cells from all $3 \mathrm{~mL}$ were resuspended, pooled and spun onto slides with a Cytopro Cytocentrifuge (Wescor Inc. Logan, UT, USA) and stained with DiffQuik (Dade Behring, Newark, DE, USA). Counts of the cells determined the differential ratio of cell types in 200 cells per slide per mouse. Tracheae were removed, after BAL collection, and trachea epithelial cells were harvested from the trachea by scraping and placed in $500 \mu \mathrm{L}$ of Tris- $\mathrm{HCl}(50 \mathrm{mM}$, $\mathrm{pH}$ 7.4) lysis buffer with protease inhibitors as previously described [30]. Trachea epithelial cells were then homogenized, sonicated and spun at $10,000 \mathrm{~g}$ at $4{ }^{\circ} \mathrm{C}$ in an ultracentrifuge. These samples were then flash frozen in liquid nitrogen and stored at $-80^{\circ} \mathrm{C}$ until assayed for PKC activity.

\subsection{Lung Histology}

After BAL, whole lungs were excised and inflated to $10 \mathrm{~cm} \mathrm{H}_{2} \mathrm{O}$ pressure with $10 \%$ formalin (Sigma-Aldrich, St. Louis, MO, USA) solution to preserve pulmonary architecture. The lungs were embedded in paraffin and sections $(4-5 \mu \mathrm{m})$ were cut and stained with hematoxylin and eosin (Sigma-Aldrich, St. Louis, MO, USA).

\subsection{PKC Isoform Assay}

From the previously frozen tracheal epithelial samples, the cell supernatant was removed (cytosolic fraction) and the cell pellet resuspended in cell lysis buffer [31] containing 0.01\% Triton X-100 and sonicated again (particulate fraction). PKC isoform activity was determined in these tracheal cytosolic and particulate samples similar to methods described previously [31]. Tracheal epithelial cells have functional $\alpha, \beta, \delta, \varepsilon$, and $\zeta$ PKC isoforms [32]. To measure specific PKC isoform activity, $24 \mu \mathrm{g} / \mathrm{mL}$ PMA, $30 \mathrm{mM}$ dithiotreitol, $150 \mu \mathrm{M}$ ATP, $45 \mathrm{mM} \mathrm{Mg}$-acetate, PKC isoform-specific substrate peptide, and $10 \mu \mathrm{Ci} / \mathrm{mL}\left[\gamma_{-}{ }^{32} \mathrm{P}\right]$-ATP were mixed in a Tris-HCl buffer ( $\left.\mathrm{pH} 7.5\right)$. Samples were cooled to $4{ }^{\circ} \mathrm{C}$. Samples $(20 \mu \mathrm{L})$ were added to $40 \mu \mathrm{L}$ of the reaction mix and incubated for $15 \mathrm{~min}$ at $30^{\circ} \mathrm{C}$. This mixture $(60 \mu \mathrm{L})$ was then spotted onto P-81 phosphocellulose papers (Whatman, Clinton, NJ, USA) to halt incubation, and papers were subsequently washed 5 times in $75 \mathrm{mM}$ phosphoric acid for $5 \mathrm{~min}$, washed once in $100 \%$ alcohol for $1 \mathrm{~min}$, dried, and counted in nonaqueous scintillant (National Diagnostics, Atlanta GA, USA). PKC activity was expressed in relation to the total amount of cellular protein assayed as picomoles of phosphate incorporated per minutes per milligram. Similarly, PKA activity was determined as previously described [33]. 


\subsection{Cytokine Assays}

BALF was collected and assayed after treatment for the concentration of interleukins released using a sandwich ELISA. IL-6 and IL-8 levels in BALF were assayed in duplicate and quantified by sandwich ELISA according to the manufacturer's instructions (R\&D Systems, Minneapolis, MN, USA) with minimum sensitivities of 1.6 and $2.0 \mathrm{pg} / \mathrm{mL}$, respectively. Cytokine/chemokine secretion is reported as concentration $(\mathrm{pg} / \mathrm{mL})$, respectively.

For the TNF $\alpha$-specific ELISA, assay conditions were as described above with the following exceptions: plates were coated with monoclonal anti-mouse TNF $\alpha$ at $2 \mu \mathrm{g} / \mathrm{mL}$, the secondary "bridge" antibody was biotinylated (rabbit) anti-mouse $\mathrm{TNF} \alpha$ at $200 \mathrm{ng} / \mathrm{mL}$, which was detected with steptavidin-HRP (1:200). The enzyme substrate was a two-part commercially available $\mathrm{kit}\left(\mathrm{H}_{2} \mathrm{O}_{2}\right.$ and tetramethylbenzidine, R\&D Systems). For all ELISAs, the reaction was terminated with $27.5 \mu \mathrm{L} /$ well of $8 \mathrm{M}$ sulfuric acid and plates were read at $490 \mathrm{~nm}$ or $450 \mathrm{~nm}$ in an automated ELISA reader (Dynex Technologies, Chantilly, VA. Results are expressed as pg of cytokine/mL.

\subsection{Lung Slice Protocol}

Female C57Bl/6 mice, between 7 and 9 weeks old, were sacrificed by intraperitoneal injection of $0.3 \mathrm{~mL}$ of sodium pentobarbital. The trachea was cannulated with an intravenous (IV) catheter tube with two input ports (20G Intima; Becton Dickinson) and secured with suture thread (4-0). A syringe filled with $3 \mathrm{~mL}$ of air was attached to one port while the other port was closed. The lungs were gently reinflated to approximate their total lung capacity by injecting $1.5 \mathrm{~mL}$ of air. Lungs were allowed to deflate after which a syringe filled with a warm $\left(37^{\circ} \mathrm{C}\right)$ solution of $2 \%$ agarose (type VII or VII-A: low gelling temperature; Invitrogen, Carlsbad, CA, USA) in sHBSS was attached to the second port of the catheter. Immediately after agarose inflation, the lungs were washed with ice-cold sHBSS, and the mouse carcass was cooled at $4{ }^{\circ} \mathrm{C}$ for 30-45 min. After the cool down period the lungs and heart were removed and placed in sHBSS $\left(4^{\circ} \mathrm{C}\right)$ and cooled for an additional $30 \mathrm{~min}-1 \mathrm{~h}$ to ensure the complete gelling of the agarose. A single lung lobe was removed from the respiratory tree by cutting the main bronchus. The lobe was trimmed near the bronchus to create a flat surface. The trimmed lobe was then held in place by tissue adhesive to the mounting block of the vibratome of the Electron Microscopy Sciences Tissue slicer (OTS 4500). The mounted lobe was submerged in a bath of HBSS maintained at $4{ }^{\circ} \mathrm{C}$. The lung lobe was sectioned into slices $140 \mu \mathrm{m}$ thick starting at the lung periphery. Sections were collected and transferred individually to wells of a 24-well plate containing DMEM supplemented with antibiotics fetal calf serum and anti-mycotics. The slices were kept at $37{ }^{\circ} \mathrm{C}$ and $10 \% \mathrm{CO}_{2}$ for at least 5 days prior to treatment. Twenty-four hours prior to treatment, media was changed to serum free to reduce interference with cytokine assays. Lung slices were pretreated for $24 \mathrm{~h}$ with alcohol at $80 \mathrm{mM}$ prior to $5 \% \mathrm{HDE}$ exposure. The slice experiments were performed in triplicate. Each data point represents $n=3$ or more different mice using multiple lung slices from different lobes of the lung. 


\subsection{Statistical Analyses}

Results presented in this manuscript are expressed as the mean \pm SEM of the number of animals in each group. The statistical differences between the various group means were determined using the one-way ANOVA with Bonferroni post-test (Graphpad Prism, San Diego, CA, USA). A probability of less than 0.05 was accepted as significant.

\section{Results}

\subsection{Body Weights and Mortality}

C57BL/6 mice were fed alcohol ad libitum for 6 weeks and at the 3-week halfway point, some mice (protocol designated) were exposed to $12.5 \%$ HDE intranasally for the remainder of the 6-week protocol. At the end of the 6-week protocol, it was observed that the body weights of mice in the combination alcohol + HDE group were statistically lower as compared to the control group weights $(p<0.001$, 17.9/20.1 g) (Figure 1).Additionally, 20\% of the co-exposed alcohol + HDE group died and collectively lost weight due to the treatment. The cause of the morbidity was unidentified (Figure 1).

Figure 1. C57BL/6 Mice were fed alcohol $(\mathrm{EtOH})$ for 6 weeks and were exposed to $12.5 \%$ hog barn dust extract (HDE) intranasally for 3 weeks $(n=5)$. Body weights of the alcohol + HDE group were statistically lower as compared to control group weights $(17.9 / 20.1 \mathrm{~g})(* p<0.05$ vs. control ANOVA, Bonferroni post-test).

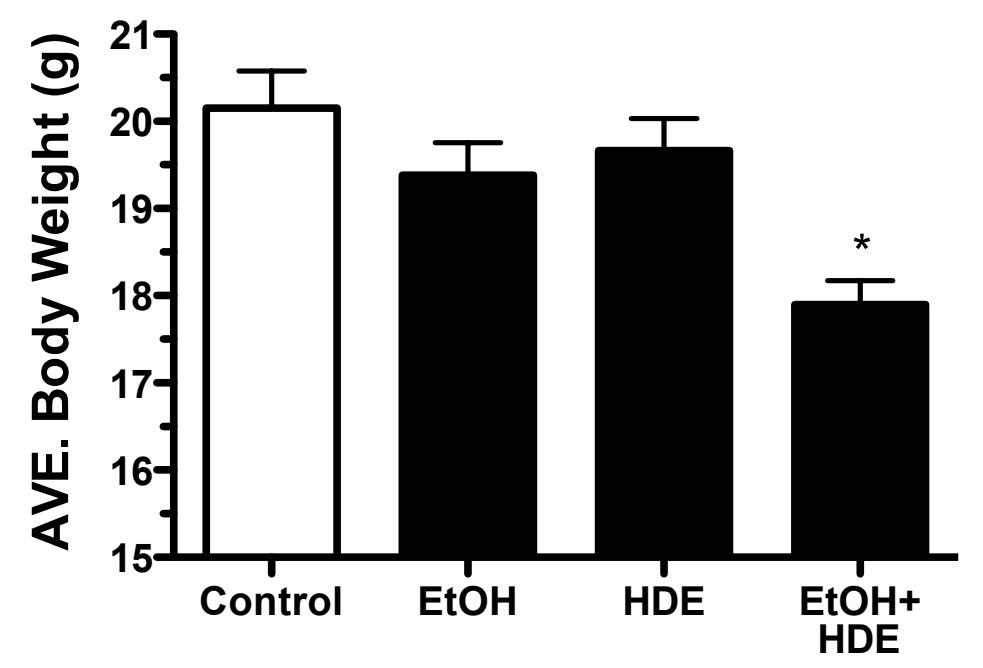

\subsection{Inflammatory Cells}

Twenty-four hours after the final HDE instillation BAL fluid was collected, the cells were counted and the total cell counts were not significantly different between the combined alcohol + HDE group and the HDE alone group. However, the distribution of cell types differed based on treatment groups. The percentage of neutrophils increased from less than $1 \%$ in the control group to $65 \%$ in the HDE group. However, a significant decrease (37\% reduction) in BAL neutrophils was observed in the alcohol + HDE group as compared to the HDE group (Figure 2). 
Figure 2. C57BL/6 Mice were fed alcohol $(\mathrm{EtOH})$ for 6 weeks and were exposed to $12.5 \%$ HDE intranasally for 3 weeks $(n=5)$. (A) Total cells counted in BALF: Total cellularity collected in the bronchoalveolar lavage fluid (BALF) increased nearly 10-fold in the HDE and alcohol + HDE groups however there is no statistical difference between the HDE and co-exposure group. (B) Total cells counted in BALF per cell type: Inflammatory cells quantified from BALF detailed a statistical increase in neutrophils in the HDE group, which is followed by a reduction in neutrophils in the alcohol + HDE group. Inflammatory cells quantified from BALF detailed a difference in distribution between alcohol + HDE and the HDE group alone. (C) Percentage of each type of cells coutnted: Neutrophils increased from less than $1 \%$ in the control to $65 \%$ in the HDE group and back down to $37 \%$ in the alcohol + HDE group. (* $p<0.05 v s$. control ANOVA, Bonferroni post-test) $(\mathrm{M}=$ macrophages, $\mathrm{P}=$ neutrophils, $\mathrm{EO}=$ eosinophils, $\mathrm{L}=$ lymphocytes $)$.
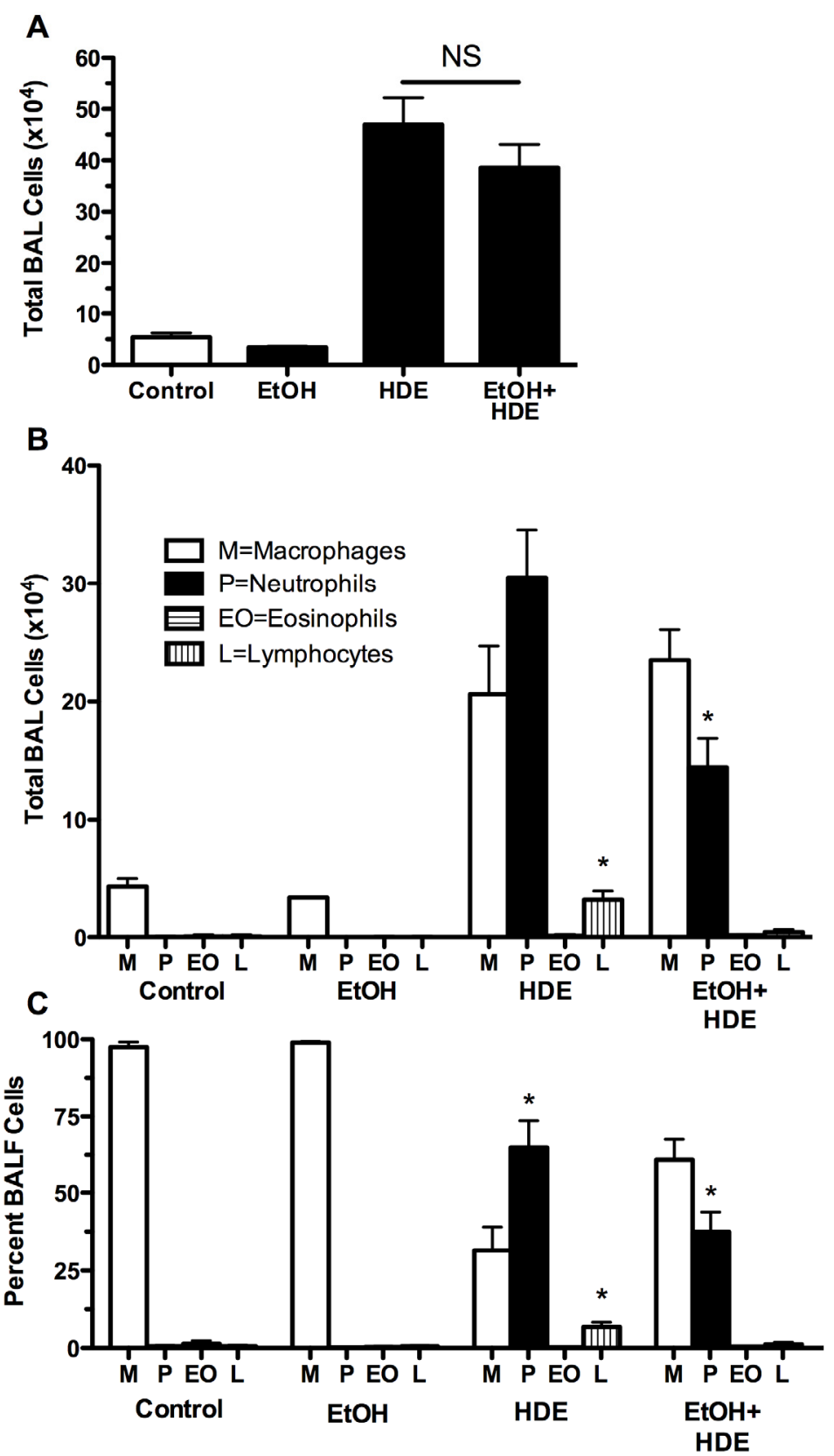


\subsection{Cytokines}

After the completion of the 6-week alcohol feeding and HDE instillation protocol, cytokines in the BAL fluid were quantified. We observed approximately a 50\% reduction in BAL IL-6 levels in the alcohol + HDE exposed group as compared to the HDE only group ( $p<0.01,46.8 / 96.1 \mathrm{pg} / \mathrm{mL}$; Figure 3). Similar patterns were seen with KC (34.1/79.6 pg/mL) and MIP-2 $(23.1 / 31.5 \mathrm{pg} / \mathrm{mL})$ (Figure 3). Alcohol treatment attenuated HDE-induced TNFa stimulation by $65 \%(117.6 / 334.1 \mathrm{pg} / \mathrm{mL})$ as compared to the HDE only group (Figure 4).

Figure 3. C57BL/6 Mice were fed alcohol $(\mathrm{EtOH})$ for 6 weeks and were exposed to $12.5 \%$ HDE intranasally for 3 weeks $(n=5)$. BAL fluid was collected from these mice and cytokine levels were quantified via ELISA. (A) IL-6 was $\sim 50 \%$ less in the alcohol + HDE group as opposed to the HDE only group (46.8/96.1 pg/mL); (B) KC quantification detailed a statistically significant reduction in the alcohol + HDE group compared to HDE only group (34.1/79.6 pg/mL); (C) MIP-2 quantification detailed a statistically significant reduction in the alcohol + HDE $v s$. the HDE only group $(23.1 / 31.5 \mathrm{pg} / \mathrm{mL})(* p<0.05 v s$. control ANOVA, Bonferroni post-test; ${ }^{\#} p<0.05$ vs. HDE, ANOVA, Bonferroni post-test).
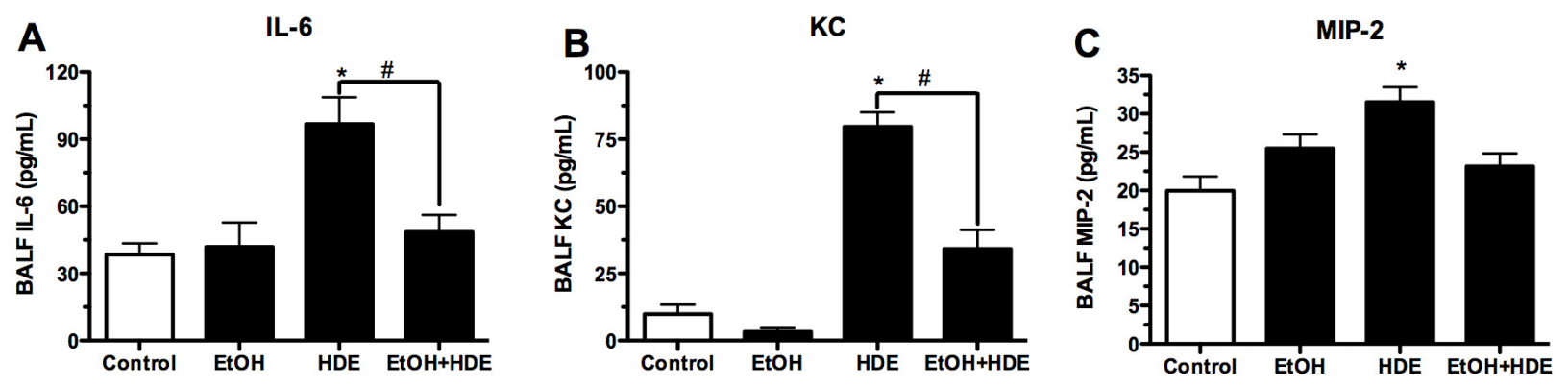

Figure 4. $\mathrm{C} 57 \mathrm{BL} / 6$ Mice were fed alcohol $(\mathrm{EtOH})$ for 6 weeks and were exposed to $12.5 \%$ HDE intranasally for 3 weeks $(n=5)$. Cytokine in the BAL fluid collected from these mice was quantified by ELISA. HDE instillation elevated TNF release more than 3 -fold vs. control ( $* p<0.05 v s$. control, ANOVA, Bonferroni post-test). TNF- $\alpha$ levels were reduced by $65 \%$ in the alcohol + HDE group compared to the HDE only group (117.6/334.1 pg/mL). ( ${ }^{\#} p<0.05$ vs. HDE, ANOVA, Bonferroni post-test).

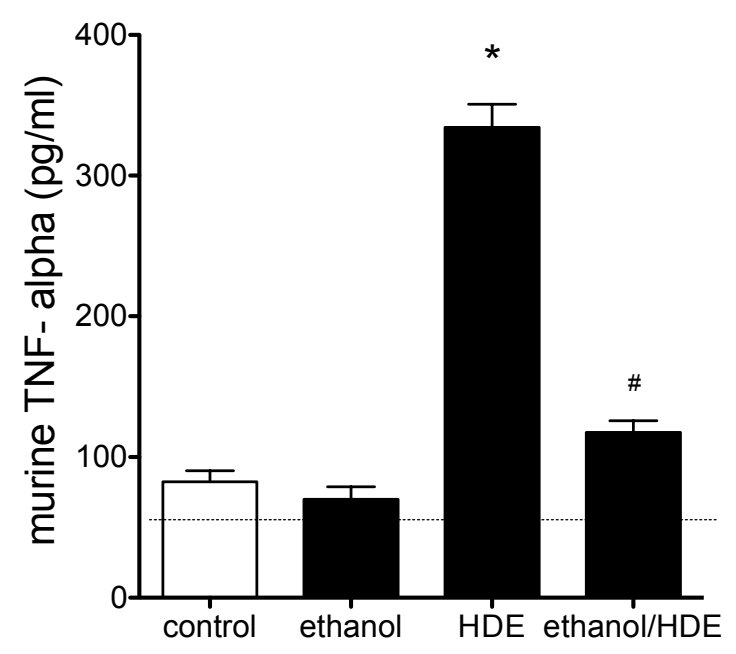




\subsection{Protein Kinase Activity}

Protein kinase activity was quantified from the tracheal epithelial cells removed from alcohol-fed and HDE-instilled mice. Protein kinase $\mathrm{C}$ epsilon (PKCE) activity in the tracheal epithelial cells of the alcohol + HDE exposed mice was $~ 50 \%$ less than activity in the HDE only group $(622.2 / 1255.5 \mathrm{pmol} / \mathrm{mg} / \mathrm{min})$ (Figure 5). PKC- $\varepsilon$ activity in the lung slices of alcohol + HDE exposed mice was $\sim 80 \%$ less than the activity in the HDE only group (404.1/2058.5 pmol/mg/min) (Figure 6). The protein kinase A activity in the tracheal epithelial cells of alcohol + HDE exposed mice was $\sim 52 \%$ lower than the HDE only exposed mice (261.1/544.6 pmol/mg/min) (Figure 5).

Figure 5. C57BL/6 Mice were fed alcohol $(\mathrm{EtOH})$ for 6 weeks and were exposed to $12.5 \%$ HDE intranasally for 3 weeks $(n=5)$. Protein kinase activity was quantified from the tracheal epithelium removed from these mice. (A) PKCE activity in the tracheal epithelial cells of the alcohol + HDE group was statistically significantly lower as compared to the HDE only group $\left.(622.2 / 1255.5 \mathrm{pmol} / \mathrm{mg} / \mathrm{min}){ }^{\#} p<0.05\right)$; (B) PKC $\alpha$ activity in tracheal epithelial cells was unchanged in the epithelial cells unchanged in the treatment groups; (C) PKA activity in the tracheal epithelial cells of the alcohol + HDE treated mice was $\sim 50 \%$ lower than the HDE only treated mice $(261.1 / 544.6 \mathrm{pmol} / \mathrm{mg} / \mathrm{min})$ $\left({ }^{\#} p<0.05\right)$.
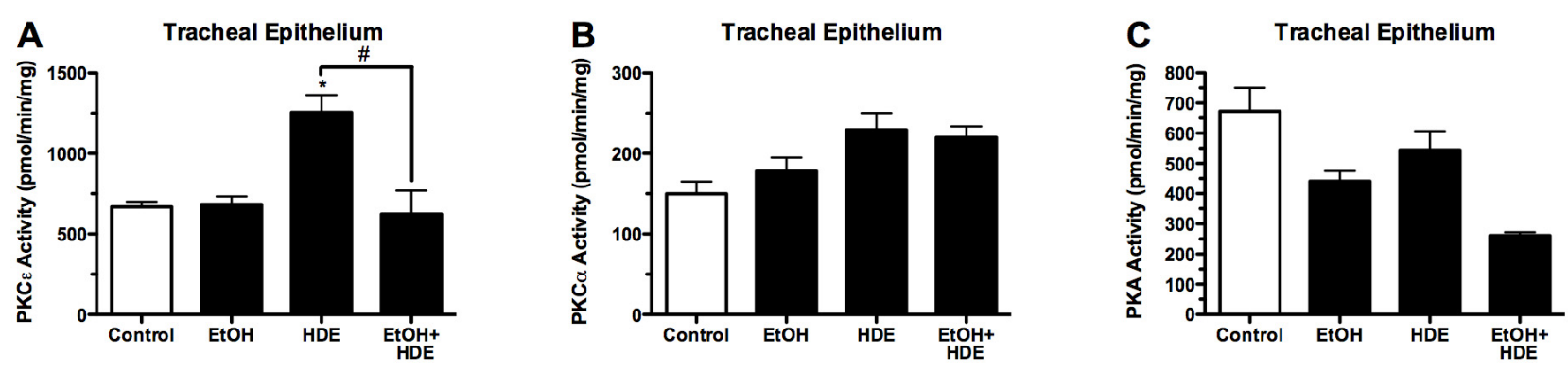

Figure 6. C57BL/6 Mice were fed alcohol $(\mathrm{EtOH})$ for 6 weeks and were exposed to $12.5 \% \mathrm{HDE}$ intranasally for 3 weeks $(n=5)$. Protein kinase activity was quantified from the ex-vivo lung tissue removed from $\mathrm{C} 57 \mathrm{Bl} / 6$ mice. (A) PKCE activity in the lung slices of the alcohol $+\mathrm{HDE}$ treated tissue was $\sim 80 \%$ less than the activity of observed in the HDE only group (404.1/2058.5 pmol/mg/min); (B) PKCa activity in the lung slices of C57B1/6 mice treated with alcohol + HDE and HDE only were both statistically higher than the control; (C) PKA activity was unchanged between treatment groups $\left({ }^{*}{ }^{*} p<0.05\right.$ vs. control ANOVA, Bonferroni post-test).
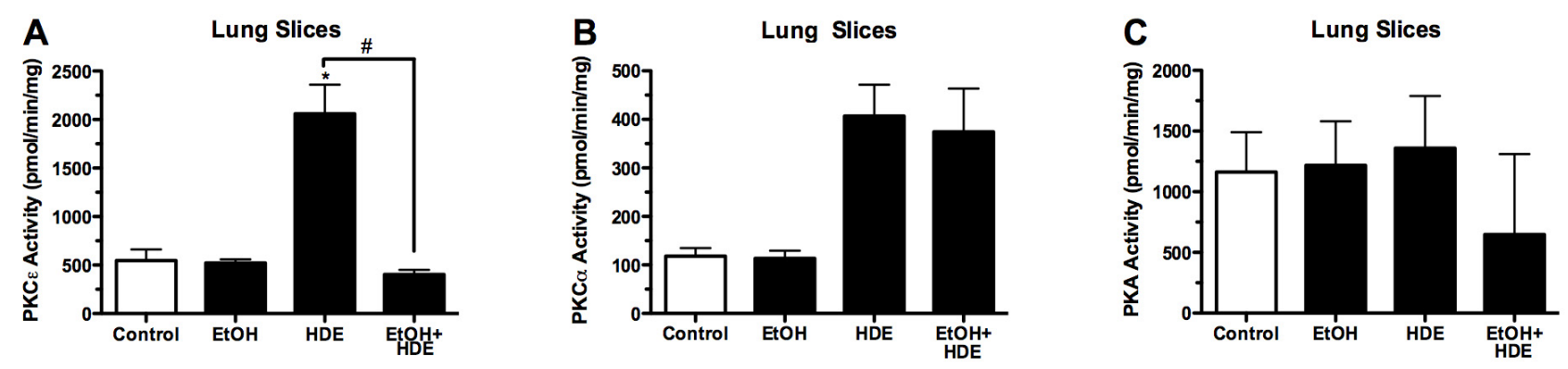


\subsection{Lung Histology}

At the completion of the treatment protocol and following BAL collection, lung tissue was stained with hematoxalyn and eosin (H\&E) and underwent qualitative analysis. The mice exposed to HDE had noticeable mononuclear cellular aggregates indicative of high levels of peribroncholar inflammation. The lungs of mice exposed to 6 weeks of 20\% alcohol ad libitum and 12.5\% HDE nasally instilled for 3 weeks showed marked reduction of mononuclear cellular aggregates (Figure 7).

Figure 7. C57BL/6 Mice were fed alcohol $(\mathrm{EtOH})$ for 6 weeks and were exposed to $12.5 \%$ HDE intranasally for 3 weeks $(n=5)$. Lung sections from H\&E stained slides revealed upon histological evaluation that HDE exposed C57BL/6 mice exhibited the highest levels of peribronchial inflammation. The alcohol + HDE exposed group showed a marked reduction in HDE-induced mononuclear cellular aggregates.
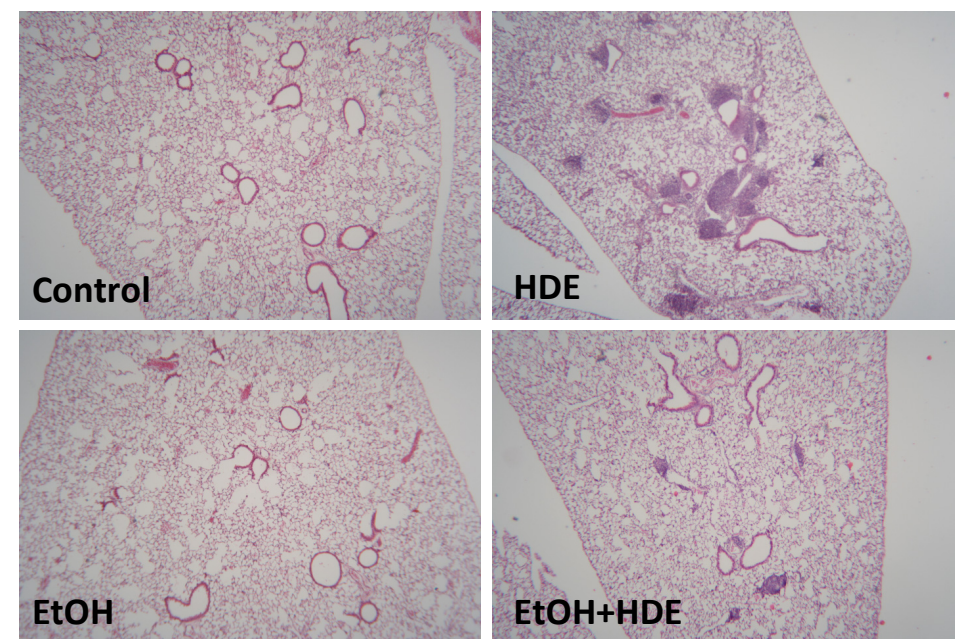

\section{Discussion}

In an inflammatory state induced by HDE inhalation, it has been observed by our group that the HDE-induced inflammatory insult is followed by rapid PKC $\alpha$ activity, which stimulates TNF $\alpha$ release that induces IL-6 and PKC $\varepsilon$ stimulation concluding with a subsequent increase of IL-8 activity [17,34] (Figure 8). The observed data presented in this manuscript parallels this previously published sequential signaling. In accord with previously published manuscripts [26,35,36], HDE exposure in our experiments caused robust statistical increases in inflammatory cell recruitment, mediator release, protein kinase $\mathrm{C}$ activity, and lung pathology development. In the HDE-only exposed group we observed increases in levels of IL-6, IL-8, TNFa, PKCe and PKA, all of which promote the inflammatory response. However, when alcohol was fed to HDE-exposed mice via the Meadows \& Cook model, much of the HDE-induced inflammatory response was muted, or in the case of some cytokines, completely abrogated. These data suggest that the consumption of alcohol interrupts the inflammatory process by inhibiting signaling such as KC, MIP-2 (IL-8) and IL-6, along with down regulating the activity of $\mathrm{PKC} \varepsilon$ in the co-exposed $\mathrm{HDE}+$ alcohol group. Alcohol-mediated protein kinase inhibition has been observed and cited in prior in vitro-based publications [37,38]. Our current data show that PKA inhibition by alcohol is also present in the in vivo model. Interestingly enough, 
HDE exposure statistically increased PKC $\alpha$ levels in the lung tissues and tracheal epithelial cells of mice, however unlike PKCE and PKA, co-administration of alcohol and HDE did not reduce PKC $\alpha$ levels. This observation is key because PKC $\alpha$ has been shown to stimulate the cascade of signaling that regulate IL-6 release, PKC $\varepsilon$ and subsequent IL-8 release [17]. Our data shows that alcohol consumption inhibits this $\mathrm{PKC} \alpha$ initiated inflammatory response, and the lack of a subsequent KC/MIP-2 (IL-8) protein increase, under pro-inflammatory conditions, led us to conclude that the signaling disruption may be occurring between the PKC $\alpha$ activation and IL- 6 vitiation. In our proposed sequential model [17] (Figure 8), TNF $\alpha$ represents an intermediate in the pathway between PKC $\alpha$ and chemokine release.

Figure 8. Proposed mechanism by which alcohol exposure ablates HDE-induced inflammation.

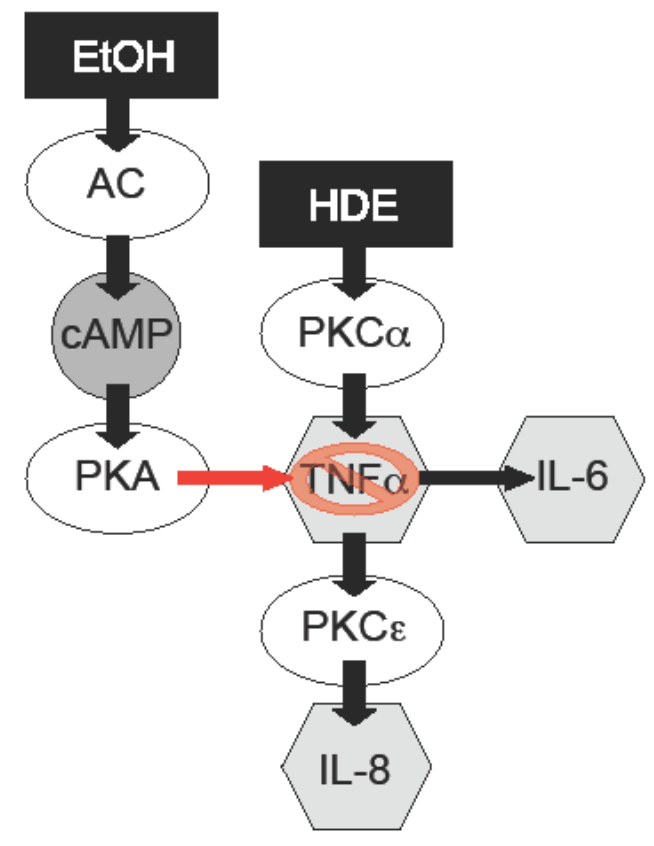

$\mathrm{TNF} \alpha$ is a cytokine that mediates inflammatory responses via the NF-kB pathway. Previously, our group have shown that TNF $\alpha$ protein stimulates PKCE but not PKC $\alpha$ [17], and subsequently TNF $\alpha$ stimulates IL-6 and IL-8 (KC/MIP-2) [19], which in turn induces neutrophil migration to the site of inflammation [39]. Even though total levels of BALF cells were statistically indifferent, in our data, neutrophil levels in the BALF were statistically lower as a proportion of total inflammatory cell counts in the alcohol + HDE group as compared to the HDE group. This is important because neutrophils are the first of the inflammatory cells to migrate towards the site of inflammation or injury [40], and these neutrophils are called to the site of inflammation by the potent neutrophil chemokine, IL- 8 (KC/MIP) [41]. With alcohol attenuating HDE-stimulated release of IL-8 mouse homologues (KC/MIP-2), a reduction of neutrophils in BALF is an expected response $[41,42]$.

Peribronchiolar inflammatory cell aggregates normally generated by the mouse lung's response to HDE were not as prevalent in the alcohol + HDE-exposed mice. This lack of cellular aggregates is likely mediated by decreased neutrophil activity. Neutrophils themselves are potent proinflammatory mediators [43], and the effect of the absence of neutrophils in an in vivo model under the influence of highly inflammatory insult such as HDE was previously unknown. 
In our study, we observed 20\% (2/10) mouse mortality. Even though $n=10$ is a small sample size, the statistical reduction of body weights in the co-exposed group shows that there was a level of general malaise in the group, which was unexpected and led us to speculate that alcohol's interference in the function of TNF $\alpha$ in a high inflammatory environment could be a reason for these deleterious results observed in the alcohol + HDE co-exposed group. Alcohol has been shown to inhibit neutrophil cytokines including TNF $\alpha$ release [44], IL-8, and NF-kB activation [45]. According to Taieb et al. 2002, this inhibition is, in part, attributed to alcohol's ability to inhibit the expression and function of TNF converting enzyme (TACE) [44]. TACE is an enzyme that proteolytically cleaves membrane bound TNF $\alpha$ allowing for soluble TNF $\alpha$ to be active. Pulmonary epithelial cells cannot mount a proper TNF $\alpha$-mediated response to an inflammatory mediator such as HDE without soluble TNF $\alpha$ [46]. These data have shown an inhibition of said TNF $\alpha$-mediated response by alcohol in the presence of a robust inflammatory initiator. As a result under pro-inflammatory pressures, the inhibition of TACE will lead to increased levels of membrane-bound TNF $\alpha$ which could potentially stimulate some TNF $\alpha$-mediated responses [47], not the least of which could be cachexia [48]. We acknowledge that serum TNF $\alpha$ levels, liver TNF $\alpha$ levels and an autopic pathological evaluation would be useful in elucidating the unexpected morbidity and mortality. Studies are being conducted to further characterize observations detailed in this manuscript. However with the weight loss and mortality data we have currently, it is possible to postulate that the mice in the co-exposed group were entering various levels of cachexia. This may seem to be contradictory to the TNF $\alpha$ data presented, however it has been observed that elevated levels of TNF $\alpha$ resulting from chronic alcohol can be attenuated with acute larger doses of alcohol [49]. Concurrently it is well documented that alcohol reflux within the lungs due to the exhalation and condensation of alcohol onto the muscosal layer of the upper airways exposes the lung epithelial layer to concentrations of alcohol beyond what the lungs would be exposed to systemically. However, unlike the liver, the lung does not have robust stores of enzymes primed to metabolize compounds to allow for rapid excretion. As a result, direct pulmonary epithelium exposure is prolonged, leading to possibly a more acute response to alcohol exposure locally in the lung even under systemic chronic alcohol pressures. This acute response in a chronic exposure environment may be what is mediating the attenuated TNF $\alpha$ observed in the lung tissue.

Based on the published data and our data presented here, it is reasonable to propose that alcohol interferes with the proper HDE-induced inflammatory response possibly through the TACE/TNF $\alpha$ pathway, leading to reduced IL-6, PKC $\varepsilon, \mathrm{KC} / \mathrm{MIP}-2$ activity, improper infiltrate clearance, weight loss, and mortality. Studies are currently underway to investigate the effect of alcohol on TNFa/TACE function during HDE exposure. Ultimately, these data relay the importance of a properly controlled proper inflammatory response, for when hog dust-induced inflammation is attenuated by alcohol consumption, $\mathrm{C} 57 \mathrm{Bl} / 6$ mice have morbidity and mortality of which the etiology is currently unknown.

\section{Conclusion}

In conclusion, an over-stimulated inflammatory response can lead to any number of inflammatory lung diseases such as chronic bronchitis, COPD, or asthma. In these conditions controlling inflammation is a primary goal. However, under the constant pressure of a potent inflammatory mediator such as organic dust from a swine confinement facility, alcohol's inflammatory suppression 
led to a deleterious outcome in our mouse model. Future studies will be conducted to investigate the nature and severity of the systematic failure which led to increased morbidity and mortality observed in alcohol and confinement barn dust (HDE) co-exposure models.

\section{Acknowledgments}

This material is the result of work supported with resources and the use of facilities at the VA Nebraska-Western Iowa Health Care System, Omaha, NE (Department of Veterans Affairs [I01BX000728] to TAW.) This work was supported by NIH-NIOSH (R01OH008539) to DJR, NIH-NIEHS (R01ES019325) TO JAP, NIH-NIAAA (R37AA008769) to JHS, CDC-NIOSH (U54OH010162-23509) to TAW, and NIH-NIAAA (R01AA017993) to TAW.

\section{Conflict of Interest}

The authors declare no conflict of interests.

\section{References}

1. Waldschmidt, T.J.; Cook, R.T.; Kovacs, E.J. Alcohol and inflammation and immune responses: Summary of the 2006 Alcohol and Immunology Research Interest Group (AIRIG) meeting. Alcohol 2008, 42, 137-142.

2. Zhang, P.; Bagby, G.J.; Happel, K.I.; Raasch, C.E.; Nelson, S. Alcohol abuse, immunosuppression, and pulmonary infection. Curr. Drug Abuse Rev. 2008, 1, 56-67.

3. Bailey, K.L.; Sisson, J.H.; Romberger, D.J.; Robinson, J.E.; Wyatt, T.A. Alcohol up-regulates TLR2 through a NO/cGMP dependent pathway. Alcohol. Clin. Exp. Res. 2010, 34, 51-56.

4. Elliott, M.K.; Sisson, J.H.; Wyatt, T.A. Effects of cigarette smoke and alcohol on ciliated tracheal epithelium and inflammatory cell recruitment. Am. J. Respir. Cell Mol. Biol. 2007, 36, 452-459.

5. Jacobsen, E. The metabolism of ethyl alcohol. Pharmacol. Rev. 1952, 4, 107-135.

6. Bechara, R.I.; Pelaez, A.; Palacio, A.; Joshi, P.C.; Hart, C.M.; Brown, L.A.S.; Raynor, R.; Guidot, D.M. Angiotensin II mediates glutathione depletion, transforming growth factor- $\beta 1$ expression, and epithelial barrier dysfunction in the alcoholic rat lung. Am. J. Physiol. Lung Cell. Mol. Physiol. 2005, 289, L363-L370.

7. Brown, L.A.; Harris, F.L.; Guidot, D.M. Chronic alcohol ingestion potentiates TNF-alpha-mediated oxidative stress and apoptosis in rat type II cells. Am. J. Physiol. Lung Cell. Mol. Physiol. 2001, 281, L377-L386.

8. Spurzem, J.R.; Gupta, J.; Veys, T.; Kneifl, K.R.; Rennard, S.I.; Wyatt, T.A. Activation of protein kinase a accelerates bovine bronchial epithelial cell migration. Am. J. Physiol. Lung Cell. Mol. Physiol. 2002, 282, L1108-L1116.

9. Goral, J.; Choudhry, M.A.; Kovacs, E.J. Acute alcohol exposure inhibits macrophage IL-6 production: Role of p38 and ERK1/2 MAPK. J. Leukoc. Biol. 2004, 75, 553-559.

10. Glover, M.; Cheng, B.; Fan, R.; Pruett, S. The role of stress mediators in modulation of cytokine production by alcohol. Toxicol. Appl. Pharmacol. 2009, 239, 98-105. 
11. Song, K.; Zhao, X.J.; Marrero, L.; Oliver, P.; Nelson, S.; Kolls, J.K. Alcohol reversibly disrupts TNF-alpha/TACE interactions in the cell membrane. Respir. Res. 2005, 24, doi:10.1186/ 1465-9921-6-123.

12. Zhao, X.; Marrero, L.; Song, K.; Oliver, P.; Chin, S.Y.; Simon, H.; Schurr, J.R.; Zhang, Z.; Thoppil, D.; Lee, S.; et al. Acute alcohol inhibits TNF- $\alpha$ processing in human monocytes by inhibiting TNF/TNF- $\alpha$-converting enzyme interactions in the cell membrane. J. Immunol. 2003, 170, 2923-2931.

13. Eduard, W.; Pearce, N.; Douwes, J. Chronic bronchitis, COPD, and lung function in farmers: The role of biological agents. Chest 2009, 136, 716-725.

14. Dosman, J.A. Respiratory response to endotoxin and dust predicts evidence of inflammatory response in volunteers in a swine barn. Am. J. Ind. Med. 2006, 49, 761-766.

15. Poole, J.A.; Wyatt, T.A.; Kielian, T.; Oldenburg, P.; Gleason, A.M.; Bauer, A.; Golden, G.; West, W.W.; Sisson, J.H.; Romberger, D.J. Toll-Like Receptor 2 (TLR2) regulates organic dust-induced airway inflammation. Am. J. Respir. Cell Mol. Biol. 2011, 45, 711-719.

16. Slager, R.E.; Allen-Gipson, D.S.; Sammut, A.; Heires, A.; de Vasure, J.; von Essen, S.G.; Romberger, D.J.; Wyatt, T.A. Hog barn dust slows airway epithelial cell migration in vitro through a PKC $\alpha$-dependent mechanism. Am. J. Physiol. Lung Cell. Mol. Physiol. 2007, 293, L1469-L1474.

17. Wyatt, T.A.; Slager, R.E.; Heires, A.J.; de Vasure, J.M.; von Essen, S.G.; Poole, J.A.; Romberger, D.J. Sequential activation of protein kinase $\mathrm{C}$ isoforms by organic dust is mediated by tumor necrosis factor. Am. J. Respir. Cell Mol. Biol. 2010, 42, 706-715.

18. Wang, Z.; Malmberg, P.; Ek, A.; Larsson, K.; Palmberg, L. Swine dust induces cytokine secretion from human epithelial cells and alveolar macrophages. Clin. Exp. Immunol. 1999, 115, 6-12.

19. Palmberg, L.; Larsson, B.; Malmberg, P.; Larsson, K. Induction of IL-8 production in human alveolar macrophages and human bronchial epithelial cells in vitro by swine dust. Thorax $\mathbf{1 9 9 8 ,}$ $53,260-264$.

20. Stallones, L.; Xiang, H. Alcohol consumption patterns and work-related injuries among colorado farm residents. Am. J. Prev. Med. 2003, 25, 25-30.

21. Schoeneberger, M.L.; Leukefeld, C.G.; Hiller, M.L.; Godlaski, T. Substance abuse among rural and very rural drug users at treatment entry. Am. J. Drug Alcohol Abuse 2006, 32, 87-110.

22. Substance Abuse and Mental Health Services Administration. Results from the 2008 National Survey on Drug use and Health: National Findings; NSDUH Series H-36, HHS Publication No. SMA 09-4434; Substance Abuse and Mental Health Services Administration: Rockville, MD, USA, 2009.

23. Glover, M.; Pruett, S.B. Role of corticosterone in immunosuppressive effects of acute alcohol exposure on toll-like receptor mediated cytokine production. J. Neuroimmune Pharmacol. 2006, $1,435-442$.

24. Pruett, S.B.; Fan, R.; Zheng, Q.; Myers, L.P.; Hébert, P. Modeling and predicting immunological effects of chemical stressors: Characterization of a quantitative biomarker for immunological changes caused by atrazine and alcohol. Toxicol. Sci. 2003, 75, 343-354. 
25. Romberger, D.J.; Bodlak, V.; von Essen, S.G.; Mathisen, T.; Wyatt, T.A. Hog barn dust extract stimulates IL-8 and IL-6 release in human bronchial epithelial cells via PKC activation. J. Appl. Physiol. 2002, 93, 289-296.

26. Poole, J.A.; Wyatt, T.A.; Oldenburg, P.J.; Elliott, M.K.; West, W.W.; Sisson, J.H.; von Essen, S.G.; Romberger, D.J. Intranasal organic dust exposure-induced airway adaptation response marked by persistent lung inflammation and pathology in mice. Am. J. Physiol. Lung Cell. Mol. Physiol. 2009, 296, L1085-L1095.

27. Song, K.; Coleman, R.A.; Zhu, X.; Alber, C.; Ballas, Z.K.; Waldschmidt, T.J.; Cook, R.T. Chronic alcohol consumption by mice results in activated splenic T cells. J. Leukoc. Biol. 2002, $72,1109-1116$.

28. Spitzer, J.H.; Meadows, G.G. Modulation of perforin, granzyme A, and granzyme B in murine Natural Killer (NK), IL2 stimulated NK, and lymphokine-activated killer cells by alcohol consumption. Cell. Immunol. 1999, 194, 205-212.

29. Elliott, M.K.; Sisson, J.H.; West, W.W.; Wyatt, T.A. Differential in vivo effects of whole cigarette smoke exposure versus cigarette smoke extract on mouse ciliated tracheal epithelium. Exp. Lung Res. 2006, 32, 99-118.

30. Wyatt, T.A.; Spurzem, J.R.; May, K.; Sisson, J.H. Regulation of ciliary beat frequency by both PKA and PKG in bovine airway epithelial cells. Am. J. Physiol. 1998, 275, L827-L835.

31. Wyatt, T.A.; Schmidt, S.C.; Rennard, S.I.; Tuma, D.J.; Sisson, J.H. Acetaldehyde-stimulated PKC activity in airway epithelial cells treated with smoke extract from normal and smokeless cigarettes. Proc. Soc. Exp. Biol. Med. 2000, 225, 91-97.

32. Albert, C.J.; Ford, D.A. Protein kinase C translocation and PKC-dependent protein phosphorylation during myocardial ischemia. Am. J. Physiol. 1999, 276, H642-H650.

33. Wyatt, T.A.; Forget, M.A.; Sisson, J.H. Alcohol stimulates ciliary beating by dual cyclic nucleotide kinase activation in bovine bronchial epithelial cells. Am. J. Pathol. 2003, 163, 1157-1166.

34. De Forge, L.E.; Remick, D.G. Kinetics of TNF, IL-6, and IL-8 gene expression in LPS-stimulated human whole blood. Biochem. Biophys. Res. Commun. 1991, 174, 18-24.

35. Bailey, K.L.; Wyatt, T.A.; Romberger, D.J.; Sisson, J.H. Alcohol functionally upregulates toll-like receptor 2 in airway epithelial cells. Alcohol. Clin. Exp. Res. 2009, 33, 499-504.

36. Wyatt, T.A.; Sisson, J.H.; von Essen, S.G.; Poole, J.A.; Romberger, D.J. Exposure to hog barn dust alters airway epithelial ciliary beating. Eur. Respir. J. 2008, 31, 1249-1255.

37. Thiele, T.E.; Willis, B.; Stadler, J.; Reynolds, J.G.; Bernstein, I.L.; McKnight, G.S. High alcohol consumption and low sensitivity to alcohol-induced sedation in protein kinase A-mutant mice. J. Neurosci. 2000, 20, RC75:1-RC75:6.

38. Wyatt, T.A.; Kharbanda, K.K.; Tuma, D.J.; Sisson, J.H. Malondialdehyde-acetaldehyde-adducted bovine serum albumin activates protein kinase $\mathrm{C}$ and stimulates interleukin- 8 release in bovine bronchial epithelial cells. Alcohol 2001, 25, 159-166.

39. Hammond, M.E.; Lapointe, G.R.; Feucht, P.H.; Hilt, S.; Gallegos, C.A.; Gordon, C.A.; Giedlin, M.A.; Mullenbach, G.; Tekamp-Olson, P. IL-8 induces neutrophil chemotaxis predominantly via type I IL-8 receptors. J. Immunol. 1995, 155, 1428-1433.

40. De Larco, J.E.; Wuertz, B.R.; Furcht, L.T. The potential role of neutrophils in promoting the metastatic phenotype of tumors releasing interleukin-8. Clin. Cancer Res. 2004, 10, 4895-4900. 
41. Kunkel, S.L.; Standiford, T.; Kasahara, K.; Strieter, R.M. Interleukin-8 (IL-8): The major neutrophil chemotactic factor in the lung. Exp. Lung Res. 1991, 17, 17-23.

42. Papoff, P.; Fiorucci, P.; Ottaviano, C.; Bucci, G. Interleukin-8: A potent neutrophil chemotactic factor. Arch. Dis. Child. Fetal Neonatal Ed. 1995, 73, F54.

43. Grenier, A. Presence of a mobilizable intracellular pool of hepatocyte growth factor in human polymorphonuclear neutrophils. Blood 2002, 99, 2997-3004.

44. Taieb, J.; de larche, C.; Ethuin, F.; Selloum, S.; Poynard, T.; Gougerot-Pocidalo, M.A.; Chollet-Martin, S. Alcohol-induced inhibition of cytokine release and protein degranulation in human neutrophils. J. Leukoc. Biol. 2002, 72, 1142-1147.

45. Jonsson, H.; Allen, P.; Peng, S.L. Inflammatory arthritis requires foxo3a to prevent fas ligand-induced neutrophil apoptosis. Nat. Med. 2005, 11, 666-671.

46. Black, R.A.; Rauch, C.T.; Kozlosky, C.J.; Peschon, J.J.; Slack, J.L.; Wolfson, M.F.; Castner, B.J.; Stocking, K.L.; Reddy, P.; Srinivasan, S.; et al. A metalloproteinase disintegrin that releases tumour-necrosis factor-alpha from cells. Nature 1997, 385, 729-733.

47. Moss, M.L.; Sklair-Tavron, L.; Nudelman, R. Drug insight: Tumor necrosis factor-converting enzyme as a pharmaceutical target for rheumatoid arthritis. Nat. Clin. Pract. Rheumatol. 2008, 4 , 300-309.

48. Aggarwal, B.B. Tumour necrosis factors receptor associated signalling molecules and their role in activation of apoptosis, JNK and NF-kappaB. Ann. Rheum. Dis. 2000, 59 (Suppl. 1), i6-i16.

49. Nelson, S.; Bagby, G.I.; Bainton, B.G.; Summer, W.R. The effects of acute and chronic alcoholism on tumor necrosis factor and the inflammatory response. J. Infect. Dis. 1989, 160, 422-429.

(C) 2012 by the authors; licensee MDPI, Basel, Switzerland. This article is an open access article distributed under the terms and conditions of the Creative Commons Attribution license (http://creativecommons.org/licenses/by/3.0/). 